\title{
Issues on Purification of Surgical Instruments Practice from Najasah (Najis) of a Dog
}

Mohd Ariffullah Ariffin, Aizat Soldin, Shukrimi Awang

Department of Orthopaedic, Traumatology \& Rehabilitation, International Islamic University Malaysia

Introduction: From Quran, dogs were mentioned several times in different perspectives. Surah al-Maidah, informs that a hunting dog's catch is lawful to be eaten. An authentic hadith about a prostitute who gave water to a dog and her sins were forgiven and was promised heaven. Case report: MrJ, 35 years old gentleman, sustained $3 \mathrm{~cm} \times 2 \mathrm{~cm}$ over left leg following a dog bite. Patient underwent emergency operation and appropriate antibiotic given. After operation, the nurse had washed entire surgical instruments with taharah soap, washed it again six times with water and followed by enzymatic detergent before sending for autoclaving. Discussion: The status of dog impurities and how to clean it derived from hadith narrated by Abu Hurairah: 'Rasulullah PBUH said: 'Cleaning a utensil that has been licked by $a$ dog is by washing it seven times and one of the washing cycle is mixed with soil". Majority Muslims in Malaysia follow Shafi'i sect, where dog's saliva and all its body are considered ritually mughallazah. Thus, if touched, they are required to cleanse the body part that came into contact with a specific Islamic ritual as mentioned. Up to date, there is no official guideline from KKM or JAKIM related to this. Surgical instruments used for the operation related to dog bite injury were not in direct contact with the dog. This practice imposes unnecessary steps for staffs. Apart from that, there are no study done on the effect of commercially manufactured soil-based soap to surgical instruments. The information regarding content also unclear. Surgical instruments are sensitive and expensive, thus improper handling can expedite damage to the instruments. Conclusion: KKM and JAKIM are recommended to produce SOP regarding this issue. Effort should be done to produce medical grade soil-based cleansing agent. Study should be done to evaluate the safety to surgical instruments. 